\title{
Advancing social media in medical education
}

\author{
Wendy M. Davis MSc, Kendall Ho MD, Jason Last MD
}

See also page 547 and www.cmaj.ca/lookup/doi/10.1503/cmaj.150248

$\mathrm{W}$

ith rapid, grassroots adoption of social media in medical education, concerns are emerging about potential risks, while benefits may be unclear. Social media holds great value as a teaching and learning tool. Canadian medical schools need to proactively adapt their curricula to this dynamic learning landscape by incorporating social media within their teaching environments in ways that are innovative, timely and evidence-based. We discuss the value of social media as a teaching and learning tool and examine some known risks and mitigating strategies.

Within the broad category of Web-based learning, educational platforms typically exist along a spectrum, varying in the degree to which users connect and collectively create content. Although many e-learning, mobile and Web-based educational tools adhere to conventional, didactic models for knowledge transmission and dissemination, social media is user-generated and collaborative, introducing a new dimension of participatory learning. ${ }^{1}$ The penetration of these media into educational realms provides the opportunity to shift learning paradigms from an individual, constructivist model, where knowledge is constructed by the learner, to a connectivist model, where knowledge is generated by information exchange and distributed across connections between learners. ${ }^{2}$ Web-based tools such as social media support the latter model in learning within, and between, communities of practice. This evolution to connectivism, dubbed "a learning theory for the digital age," 2 can be seen in parallels between more traditional learning materials (e.g., paper-based textbooks) and their newer, sociotechnical counterparts (e.g., collaboratively created "wikis").

Although social media may be a relatively novel or unfamiliar tool for some educators, today's medical students have used it extensively as a communication tool throughout their teen and early adult personal, professional and educational lives. Social media enhances medical education by including students in the explicit creation of their own knowledge and by facilitating engagement, self-reflection and active learning. For example, medical trainees may use Facebook or Google+ for online group collaboration, sharing of resources and virtual moral support from student peers. ${ }^{3}$ Educators may incorporate YouTube videos covering medical topics in classroom lectures to enhance concept delivery with animations or video demonstrations, and students may stream videos to review difficult concepts outside of class hours. ${ }^{4}$ Students may be encouraged to tweet questions during lectures or conferences, using hashtags to link related Twitter conversations. ${ }^{5}$ Some students may be asked to reflect on their training experiences by writing blog posts that can then be made available to their peers for comment or feedback. Students may collaborate in the creation of wikis related to medical topics, synthesizing information and sharing knowledge. Podcasts, photo-sharing (e.g., through Flickr or the Figure1 app) and file collaboration (e.g., through Google Drive or Dropbox) can also be used. In addition, this online milieu can stimulate peer and faculty review of posted social media content (e.g., through a comments feature) on a global platform to ensure accuracy of information, and it facilitates rapid feedback to learners from within and outside of formal learning circles. ${ }^{1,6}$ Knowledge translation and continuing professional development can be enhanced through the formation of collaborative, international online journal clubs.

A lack of established metrics within the field, compounded by logistical difficulties in collecting certain data (e.g., who is using what tools, and how), presents challenges to research. As such, there are limited data from rigorous program evaluations supporting the theoretical, and anecdotal, advantages of social media in medical education.

Although most medical trainees and many faculty already use some form of social media in edu-

\section{KEY POINTS}

- With the rapid, grassroots adoption of social media by medical trainees and teachers, medical schools need to account for and incorporate social media within their curricula.

- The use of social media holds great value as a teaching and learning tool in medical education, by including students in the creation of their own knowledge and by facilitating engagement, self-reflection and active learning.

- Proactive policies and training can effectively mitigate risks and challenges associated with the use of social media in medical education (e.g., confidentiality breaches and professionalism concerns). 
cation, institutions and licensing bodies have been more conservative in their adoption of official policies and programming to endorse and support its use. This caution may be due in part to the numerous anticipated risks and challenges commonly associated with the use of social media in medicine and medical education. Social media use during lectures may be a substantial source of distraction, leading some instructors to limit its use during class time. Professionalism is also a major concern as teachers and learners manage and negotiate the boundaries between their personal and professional online identities. ${ }^{7}$ For example, private photos, perhaps inappropriate in a professional context, may be seen by others when a personal social media account is used for educational purposes. Moreover, in this connected, digital age, previously distinct personal-professional boundaries may now be more blurred because identities are represented holistically. Health professionals and trainees will thus need to navigate virtual interactions authentically yet cautiously. Preserving patient confidentiality is also of great concern, since identifiable images or patient information might be shared online without appropriate consent. Further challenges of integrating social media into mainstream medical education include the legality of sharing copyrighted educational material and other intellectual property (e.g., lecture slides and images), ${ }^{2,7}$ the global nature of social media in culling content of highly uneven quality (sometimes produced by non-experts) and potentially exposing students to wrong or misleading information,;,8 and the significant variability in the degree to which students and faculty embrace electronic and social media.

A one-size-fits-all approach will not be suitable for every learning context. ${ }^{6}$ Guidelines on the appropriate use of social media were developed by the Canadian Medical Association (CMA) and the Canadian Federation of Medical Students. ${ }^{9} 10$ The latter are targeted toward medical students and are both recent and pertinent to medical education, whereas the CMA guidelines offer limited guidance for medical educators and will need to be updated to remain current given the rapid evolution of social media.

By developing evidence-based policies related to social media use, medical schools can effectively mitigate risks to the legal, professional and ethical integrity of medical trainees and teachers. By providing training around social media and online professionalism, schools can effectively educate students and prevent or reduce lapses in professionalism and breaches of confidentiality. Some Canadian medical schools have already begun to incorporate this within their curricula. ${ }^{11}$ In addition, the provision of ongoing technical guidance will support users at all levels. Where concerns about the potential for distraction may lead some teachers to want to limit the use of social media during class time, education programs could instead seek to harness the power of the technology and aim to control social media as part of the learning process, with well thought-out strategies for engagement.

Institutions and faculty should proactively identify and highlight high-quality resources to ensure learning materials used in social media are accurate and relevant. Further research needs to substantiate and characterize best educational practices in social media and to identify optimal ways to assist institutions in integrating and implementing these approaches in their curricula. Through these policies, institutions will foster an environment that enables appropriate social mediaenhanced teaching and learning, and the cocreation of a dynamic and active learning milieu by teachers and students together.

\section{References}

1. Ho K, Peter Wall Workshop Participants. Harnessing the social web for health and wellness: issues for research and knowledge translation. J Med Internet Res 2014;16:e34.

2. Siemens G. Connectivism: a learning theory for the digital age [blog entry]. eLearnspace; 2014. Available: www.elearnspace. org/Articles/connectivism.htm (accessed 2015 Mar. 23).

3. Gray K, Annabell L, Kennedy G. Medical students' use of Facebook to support learning: insights from four case studies. Med Teach 2010;32:971-6.

4. Topps D, Helmer J, Ellaway R. YouTube as a platform for publishing clinical skills training videos. Acad Med 2013;88:192-7.

5. Junco R, Heiberger G, Loken E. The effect of Twitter on college student engagement and grades. J Comput Assist Learn 2010;27: 119-32.

6. Cheston CC, Flickinger TE, Chisolm MS. Social media use in medical education: a systematic review. Acad Med 2013;88:893-901.

7. Lie D, Trial J, Schaff P, et al. "Being the best we can be": medical students' reflections on physician responsibility in the social media era. Acad Med 2013;88:240-5.

8. Camm CF, Sunderland N, Camm AJ. A quality assessment of cardiac auscultation material on YouTube. Clin Cardiol 2013; 36:77-81.

9. Social media and Canadian physicians: issues and rules of engagement. Ottawa: Canadian Medical Association; 2011. Available: www.cma.ca/En/Pages/social-media-use.aspx (accessed 2015 Mar. 23).

10. CFMS guide to medical professionalism: recommendations for social media. Ottawa: Canadian Federation of Medical Students; 2013

11. Jalali A, Wood TJ. Teaching medical students social media: must or bust. Med Educ 2014;48:1128-9.

Additional resources are available in Appendix 1 (www.cmaj .ca/lookup/suppl/doi:10.1503/cmaj.141417/-/DC1).

Affiliations: Faculty of Medicine (Davis), University of British Columbia; Department of Emergency Medicine, and eHealth Strategy Office (Ho), Faculty of Medicine, University of British Columbia; Vancouver, BC; UCD School of Medicine and Medical Science (Last), University College Dublin, Dublin, Ireland

Contributors: All of the authors contributed substantially to the writing and revising of the manuscript, approved the final version and agreed to act as guarantors of the work.

Funding: This work was made possible by a research grant from the Universitas 21 Health Sciences Group.

Acknowledgement: The authors thank the Universitas 21 Social Media for Education in Health Working Group for their contributions to the development of the commentary. 